\title{
Особенности гемодинамики в системе легочной артерии у лиц, проживающих в условиях Крайнего Севера
}

Лаборатория инструментальных методов диагностики ГУ "НИИ медицинских проблем Крайнего Севера РАМН":

629730, Ямало-Ненецкий автономный округ, Надым, 107-й км

\section{T.K.Erdakova, L.V.Salamatina, A.A.Buganov \\ Peculiarities of pulmonary haemodynamics in residents of the Far North}

\begin{abstract}
Summary
One hundred and thirteen patients with stage I to II essential hypertension (44 males and 69 females aged of 20 to 59 years) were studied. The longer the patient dwelled at the Far North the more remodeling of pulmonary arteries progressed. At the same time, changes of temporary indices were multidirectional under condition of increasing pulmonary artery pressure. Strong correlations were found between duration of dwelling at the Far North and systolic pulmonary artery pressure, mean pulmonary artery pressures and total pulmonary vascular resistance in patients dwelling in severe climatic conditions.

Key words: pulmonary artery pressure, essential hypertension, Far North, remodeling.
\end{abstract}

\section{Резюме}

Были обследованы 113 больных артериальной гипертонией I-II стадий (44 мужчины и 69 женщин) в возрасте от 20 до 59 лет. В результате проведенного исследования установлено, что с увеличением сроков проживания в регионах высоких широт прогрессируют процессы структурно-функционального ремоделирования сосудов малого круга кровообращения, формируется разнонаправленная динамика временных показателей на фоне возрастающих показателей давления в системе легочной артерии. Получены тесные корреляционные взаимосвязи между северным стажем и показателями систолического, среднего артериального давления в системе легочной артерии, а также общим легочным сосудистым сопротивлением у лиц, проживающих в неблагоприятных климатогеографических условиях. Ключевые слова: давление в легочной артерии, артериальная гипертензия, Крайний Север, ремоделирование.

Российское Заполярье - это обширная территория, где проживает и трудится значительное количество людей. Эту географическую зону отличают особые экологические характеристики - суровый климат, резко измененная фотопериодичность (полярный день, полярная ночь), своеобразие флоры и фауны, сложный комплекс гелиогеофизических явлений, а также специфические социальные факторы.

Издавна бытует мнение, что на Крайнем Севере в атмосфере не хватает кислорода, поскольку часто у вновь прибывших на эту территорию возникает т. н. полярная одышка. Однако многочисленные исследования свидетельствуют, что процентное содержание кислорода в воздухе соответствует норме, а его весовое содержание в 1 м $^{3}$ превышает показатели средних широт на 20-30 \%. Это не случайность, т. к. плотность воздуха закономерно возрастает с понижением температуры воздуха. Причина полярной одышки, как выяснилось, заключается в повышенной потребности в кислороде, когда организм включает все механизмы, чтобы восполнить его недостаток. При этом на структурном и функциональном уровнях развиваются сложные адаптационные реакции - прежде всего, в системе легочного кровообращения [1-5].

При действии неблагоприятных климатогеографических факторов Заполярья на организм человека, прежде всего холодового, запускается целый комплекс компенсаторно-приспособительных реакций, происходит стимуляция периферических и центральных термочувствительных нервных структур, нейрогуморальных, гормональных и местных механизмов регуляции деятельности сердца и тонуса сосудов человека, что в итоге приводит к изменению легочной гемодинамики и активации процессов ремоделирования системы легочной артерии (ЛА). Патоморфологические изменения стенки ЛА, происходящие под действием неблагоприятных климатогеографических факторов высоких широт, связаны с первичным поражением прекапиллярной части легочного русла. В легочных сосудах они гистопатологически проявляются в виде пролиферации интимы и гипертрофии мышечной оболочки, которые вызывают сужение и / или облитерацию просвета ЛА [3].

Таким образом, дыхание низкотемпературным воздухом в условиях Крайнего Севера вызывает целый ряд физиологических реакций и патологических изменений гемодинамических показателей в системе ЛА. Длительное воздействие постепенно приводит к структурным изменениям, направленным на ограничение повреждающего действия агрессивного фактора и повышение эффективности нарушенной функции. В целом можно ожидать перестроек, которые направлены, с одной стороны, на снижение теплопотерь в транзиторной зоне, а с другой - на повышение эффективности массопереноса кислорода в респираторной зоне, определяя индивидуальные морфологические преобразования адаптационных 
изменений органов сердечно-легочной системы у мигрантов на севере. Несмотря на актуальность изучения особенностей гемодинамики сосудов малого круга кровообращения у лиц, проживающих в условиях севера, научные работы в этой области пока немногочисленны и противоречивы.

Цель настоящего исследования - изучить особенности гемодинамических показателей в системе ЛА у больных артериальной гипертонией (АГ) в зависимости от северного стажа (СС).

\section{Материалы и методы}

Были обследованы 113 больных АГ I-II стадий (44 мужчины и 69 женщин) в возрасте от 20 до 59 лет (средний возраст - 49,0 \pm 8,2 года), стаж заболевания которых составил 7,1 \pm 5,3 года, длительность проживания на Крайнем Севере - 23,3 \pm 8,7 года. Группу сравнения составили 30 практически здоровых лиц (10 мужчин и 20 женщин), средний возраст которых составил 47,9 $\pm 8,3$ года, с длительностью проживания на Крайнем Севере $22,4 \pm 6,7$ года. Все пациенты в зависимости от северного стажа были разделены на группы, сопоставимые по полу, возрас-

Таблица 1

Клинико-лабораторная характеристика больных $A Г$

\begin{tabular}{|c|c|}
\hline Показатели & $M \pm \sigma(n=113)$ \\
\hline Возраст, лет & $49,0 \pm 8,2$ \\
\hline Стаж заболевания, лет & $7,1 \pm 5,3$ \\
\hline СС, лет & $23,3 \pm 8,7$ \\
\hline САД, мм рт. ст. & $132,0 \pm 9,4$ \\
\hline ДАД, мм рт. ст. & $100,00 \pm 5,54$ \\
\hline ЧСС, мин ${ }^{-1}$ & $64,5 \pm 2,67$ \\
\hline Общий холестерин, моль/л & $4,2 \pm 0,9$ \\
\hline ФВ, \% & $64,94 \pm 7,65$ \\
\hline KCP, CM & $2,75 \pm 2,56$ \\
\hline КДР, см & $4,22 \pm 3,13$ \\
\hline ТМЖП, см & $1,29 \pm 3,07$ \\
\hline ТЗСЛЖ, см & $1,11 \pm 0,16$ \\
\hline ММЛЖ, г & $169,5 \pm 24,5$ \\
\hline иммлЖ, г/м² & $129,3 \pm 19,4$ \\
\hline ЖЕЛ & $85,2 \pm 0,46$ \\
\hline ФЖЕЛ & $80,4 \pm 0,69$ \\
\hline $0 Ф \mathrm{~B}_{1}$ & $79,2 \pm 0,78$ \\
\hline $\mathrm{MOC}_{25}$ & $60,4 \pm 0,56$ \\
\hline $\mathrm{MOC}_{50}$ & $58,5 \pm 0.83$ \\
\hline $\mathrm{MOC}_{75}$ & $32,4 \pm 0,95$ \\
\hline $\mathrm{MOC}_{25-75}$ & $41,9 \pm 0,49$ \\
\hline
\end{tabular}

Примечание: САД - систолическое артериальное давление; ДАД - диастолическое артериальное давление; ЧСС - частота сердечных сокращений; ФВ - фракция выброса; КСР - конечно-систолический размер; КДР - конечно-диастолический размер; ТМЖП - толщина межжелудочковой перегородки; ТЗСЛЖ - толщина задней стенки левого желудочка; ММЛЖ - масса миокарда левого желудочка; ИММЛЖ - индекс массы миокарда левого желудочка; ЖЕЛ - жизненная емкость легких; ФЖЕЛ - форсированная жизненная емкость легких; ОФВ $\mathrm{MOC}_{25}, \mathrm{MOC}_{50}, \mathrm{MOC}_{75}$ - максимальные объемные скорости потоков при выдохе 25, 50 И $75 \%$ ФЖЕЛ. ту, клинико-лабораторным показателям. 1-ю группу составили больные АГ с СС $<5$ лет - 3,01 $\pm 1,02$ года $(n=16), 2-ю-$ больные АГ с СС 5-10 лет - 7,56 1,29 года $(n=39), 3-ю-$ больные АГ с СС $>10$ лет $24,30 \pm 5,98$ года $(n=58)$. Клинико-лабораторная характеристика обследованных представлена в табл. 1.

Критериями исключения из исследования были: вторичная АГ; ДАД > 110 мм рт. ст. и / или САД выше 180 мм рт. ст.; любые тяжелые сопутствующие заболевания в стадии декомпенсации (нарушение функции печени или почек, заболевания сердца, в т. ч. застойная сердечная недостаточность, инфаркт миокарда, декомпенсированный сахарный диабет, хронические неспецифические заболевания легких и др.); любые эпизоды нарушения мозгового кровообращения в последние 2 года; беременность и лактация; злоупотребление алкоголем и употребление наркотиков; повышенная чувствительность к исследуемым препаратам в анамнезе; нежелание пациента участвовать в исследовании.

Исследование проводили на ультразвуковом аппарате Vivid-7 (США) фазированными секторными датчиками с частотой сканирования 2,5-5,0 МГц. Измерения выполняли в стандартных эхокардиографических позициях с использованием непрерывноволновой и цветовой допплерографии и режимов тканевого допплера (импульсноволнового и цветового). У всех обследованных определяли следующие эхокардиографические параметры [6-9]: индекс времени ускорения потока систолического потока ЛА (ИВУСПЛА), индекс времени замедления потока систолического потока ЛА (ИВЗСПЛА), ускорение систолического потока в ЛА (УСПЛА, м/ ${ }^{2}$ ), замедление систолического потока в ЛА (ЗСПЛА, м/ $\mathrm{c}^{2}$ ), отношение времени ускорения ко времени изгнания (ОВУСП / ВИ), диаметр ЛА (мм), СДЛА (мм рт. ст.), СрДЛА (мм рт. ст.), ДДЛА (мм рт. ст.), общее легочное сосудистое сопротивление (ЛСС, дин $\bullet$ с $・ \mathrm{cM}^{-5}$ ), давление заклинивания в ЛА (ДЗЛА, мм рт. ст.).

Статистическая обработка данных осуществлялась посредством программы Biostat. Определялись средние величины полученных данных $(M)$ и их дисперсия $(\sigma)$. Применялись непараметрические критерии: при определении ранговой корреляции - Спирмена, для оценки межгрупповых различий - Крускала-Уоллиса. При наличии корреляционной связи определялись достоверность ( $p)$ и сила этой связи $(r)$. Достоверными считались различия при $p<0,05$.

\section{Результаты}

Анализируя зависимость структурных показателей ЛА у больных АГ от сроков проживания на Крайнем Севере, выявили, что средние значения диаметра ЛА при увеличении СС достоверно уменьшались: в 1-й группе $-21,5 \pm 2,9$ мм, во 2-й - 19,6 $\pm 2,1$ мм, в 3-й $18,7 \pm 1,5$ мм (табл. 2).

При сравнении временных показателей систолического потока ЛА - ИВУСПЛА и ИВЗСПЛА - выявлена их разнонаправленная динамика: так, при длительном СС прослеживалась тенденция к увели- 
Таблица 2

Показатели гемодинамики в системе ЛА у лиц, проживающих на Крайнем Севере в зависимости от северного стажа $(M \pm \sigma)$

\begin{tabular}{|c|c|c|c|c|}
\hline \multirow[t]{2}{*}{ Показатели } & \multirow[t]{2}{*}{ Группа контроля, $n=30$} & \multicolumn{3}{|c|}{ Больные АГ } \\
\hline & & 1-я группа, $n=16$ & 2-я группа, $n=39$ & 3-я группа, $n=58$ \\
\hline Диаметр ЛА, мм & $25,7 \pm 3,3$ & $21,5 \pm 2,9$ & $19,6 \pm 2,1^{*}$ & $18,7 \pm 1,5^{*}, *$ \\
\hline ИВУСПЛА & $0,13 \pm 0,02$ & $0,12 \pm 0,01$ & $0,11 \pm 0,01$ & $0,10 \pm 0,01, \cdot$ \\
\hline ИВЗСПЛА & $0,19 \pm 0,02$ & $0,21 \pm 0,02$ & $0,23 \pm 0,03^{*}$ & $0,25 \pm 0,01, \cdot$ \\
\hline УСПЛА, $\mathrm{m} / \mathrm{c}^{2}$ & $10,5 \pm 0,7$ & $10,5 \pm 0,9$ & $12,5 \pm 0,9^{*}$ & $13,5 \pm 0,9^{*}, * *$ \\
\hline ЗСПЛА, м/ $\mathrm{c}^{2}$ & $5,9 \pm 0,3$ & $5,1 \pm 0,4$ & $4,8 \pm 0,3^{*}$ & $4,0 \pm 0,2, * *$ \\
\hline ОВуСП / ВИ & $0,51 \pm 0,02$ & $0,47 \pm 0,01^{*}$ & $0,40 \pm 0,01^{*}$ & $0,37 \pm 0,01 ;$ \\
\hline СДЛА, мм рт. ст. & $16,87 \pm 2,89$ & $22,40 \pm 3,45$ & $29,8 \pm 4,23 ;, \cdot$ & $38,9 \pm 6,39^{*},{ }^{, * *}, * *$ \\
\hline СрДЛА, мм рт. ст. & $8,59 \pm 1,35$ & $12,23 \pm 2,90$ & $18,58 \pm 3,35^{*},{ }^{* *}$ & $23,1 \pm 4,1^{*}, * * * * *$ \\
\hline ДДЛА, мм рт. ст. & $5,34 \pm 1,78$ & $7,31 \pm 2,58$ & $11,21 \pm 3,56^{*}, *$ & $17,23 \pm 4,10^{*}, * \cdots$ \\
\hline ЛСС, дин $\cdot$ С $\cdot$ См $^{-5}$ & $67,23 \pm 24,34$ & $86,0 \pm 12,0$ & $129,2 \pm 21,2^{*}, * *$ & $158,4 \pm 32,1^{*}, * *, \cdots$ \\
\hline ДЗЛА, мм рт. ст. & $4,9 \pm 1,3$ & $5,6 \pm 2,0$ & $6,1 \pm 2,9$ & $7,2 \pm 3,1$ \\
\hline
\end{tabular}

Примечание: * - p<0,05 по сравнению с контрольной группой; ** $p<0,05$ по сравнению с 1-й группой; *** - $p<0,05$ по сравнению со 2-й группой.

чению ИВУСПЛА $(0,12 \pm 0,01 ; 0,11 \pm 0,01 ; 0,10 \pm$ $0,01$ в 1,2 и 3-й группах соответственно; $p>0,05)$, тогда как ИВЗСПЛА с ростом СС, наоборот, уменьшался $(0,21 \pm 0,02 ; 0,23 \pm 0,03 ; 0,25 \pm 0,01$ в 1,2 и 3 -й группах соответственно; $p>0,05)$. При сравнении скоростных показателей кровотока в системе ЛА у больных АГ с различным длительностью СС получены следующие результаты: в 1, 2 и 3-й группах УСПЛА составило $10,5 \pm 0,9 ; 12,5 \pm 0,9$ и $13,5 \pm$ $0,9 \mathrm{~m} / \mathrm{c}^{2}$ соответственно, а ЗСПЛА - 5,1 $\pm 0,4 ; 4,8 \pm$ 0,3 и $4,0 \pm 0,2 \mathrm{~m} / \mathrm{c}^{2}$ соответственно.

Наиболее информативным показателем изменения временных гемодинамических параметров систолического кровотока в ЛА является ОВУСП / ВИ, которое достоверно уменьшалось с увеличением срока проживания в неблагоприятных климатогеографических регионах высоких широт: в 1, 2 и 3-й группах его значение составило $0,38 \pm 0,01 ; 0,32 \pm$ 0,01 и $0,30 \pm 0,01$ соответственно.

При межгрупповом анализе у больных АГ выявлено увеличение СДЛА: в 1-й группе данный показатель был больше, чем в группе контроля, на $32,5 \%$, во 2-й - на 76,3\%, в 3-й - достоверно больше в 2,3 раза. Прослеживалась тенденция повышения ДДЛА с увеличением срока жизни на Крайнем Севере: в 1-й группе - на $36,9 \%$, во 2-й - в 2,1 раза, в 3-й - в 3,2 раза. В последних 2 группах рост показателей носит достоверный характер. Значение СрДЛА в 1-й группе обследованных было в 1,5 раза выше, чем во 2-й, и на $19,9 \%$ ниже, чем в 3-й.

Для интегральной оценки структурно-функционального ремоделирования сосудов малого круга кровообращения служат показатели ЛСС, динамика изменений которого свидетельствует о прогрессировании процессов сосудистой перестройки в легочной паренхиме. Так, у больных АГ 1-й группы ЛСС увеличивалось на $28 \%$, во 2-й и 3-й группах повышение его значения было достоверным (в 1,9 и 2,4 раза соответственно) по сравнению с группой контроля.
Указанные показатели артериального давления в системе легочных сосудов прогрессивно возрастали на фоне увеличения сроков проживания в Заполярье. При этом достоверные изменения ДЗЛА отсутствовали, что может косвенно свидетельствовать о формировании первичной артериальной легочной гипертензии (ЛГ) у лиц с АГ, проживающих в условиях с неблагоприятной климатогеографической средой.

Выявлены тесные корреляционные взаимосвязи между северным стажем и показателями САД, ДАД и СрАД в системе ЛА, а также общим легочным сосудистым сопротивлением у лиц, проживающих в условиях с неблагоприятной климатогеографической средой $(r=0,62$ при $p<0,05 ; r=0,52$ при $p<0,05$; $r=0,61$ при $p<0,01 ; r=0,7$ при $p<0,01$ соответственно).

\section{Обсуждение}

Значение системы легочного кровообращения в адаптации человека к условиям Крайнего Севера весьма существенно. Легочные сосуды наряду с системой большого круга кровообрашения активно участвуют в формирование компенсаторно-приспособительных реакций к неблагоприятным климатогеографическим условиям высоких широт. Особенностями циркуляции крови по сосудам малого круга кровообащения определяются индивидуальные морфологические преобразования органов сердечно-легочной системы у мигрантов на севере. Во-первых, в легочном кровообращении градиенты давления между артериями и капиллярами, между капиллярами и левым предсердием значительно ниже, чем в соответствующих отделах большого круга кровообращения. В связи с этим сопротивление в легочных сосудах также невелико - примерно в 10 раз меньше системного периферического сопротивления [3-5]. Во-вторых, гемодинамические условия в легочных артериях остаются в основном такими же, как и в артериях 
большого круга кровообращения. Через сосуды малого круга кровообращения протекает вся кровь, выброшенная правым желудочком. Скорость нарастания и спада волн кровотока в легочной артерии не столь значительна, как в аорте, поэтому даже в период диастолы кровь течет по направлению к легким. Однако в легочной гемодинамике, несмотря на эластические свойства легочных артерий, в отличие от системной, сохраняется пульсирующий характер кровотока даже в капиллярах и венах вплоть до левого предсердия, а средняя скорость кровотока в легочной артерии в покое равна примерно $18 \mathrm{~cm} / \mathrm{c}^{-1}$. В легочных капиллярах она снижается примерно до той же величины, что и в капиллярах большого круга. В-третьих, сосуды малого круга кровообращения имеют характерное строение, обусловленное его физиологией. Легочная артерия способна значительно растягиваться и увеличивать объемный кровоток в 3-3,5 раза. Стенки крупных ветвей легочной артерии по сравнению с сосудами большого круга кровообращения (одинакового калибра) тоньше, содержат мышечные и эластические волокна, связанные мукоидной субстацией. Артериолы малого круга кровообращения существенно отличаются от артериол большого круга. Последние имеют более мощный мышечный слой и эластический каркас, поэтому легочные артериолы могут выполнять резистивную функцию при более низком артериальном давлении [3].

В связи с описанными гемодинамическими особенностями в системе малого круга кровообращения и законами гидродинамики капилляры верхних отделов легких перфузируются незначительно либо вовсе не перфузируются. Напротив, в нижних отделах легких гидростатическое давление складывается с артериальным, что приводит к дополнительному растяжению сосудов и их полнокровию. При этом кровоток в различных отделах легких оказывается неравномерным, значительно усиливаясь при напряжении кислородного режима организма в условиях высоких широт и холодовых воздействий, и в итоге развивается синдром ЛГ, что подтверждается результатами настоящего исследования.

Таким образом, можно предположить, что у обследованных больных механизмы формирования АГ и легочной АГ были различными и могли одновременно присутствовать у одних и тех же больных в высоких широтах.

\section{Заключение}

1. У больных АГ на Крайнем Севере с увеличением срока проживания прогрессируют процессы структурно-функционального ремоделирования сосудов малого круга кровообращения.

2. С увеличением длительности проживания в регионе высоких широт у больных АГ на Крайнем Севере формируется разнонаправленная динамика временных и скоростных показателей систолического кровотока на фоне возрастающих показателей давления в системе ЛА.

3. Выявлены тесные корреляционные взаимосвязи между СС и показателями САД, СрАД и ЛСС у лиц, проживающих в неблагоприятных климатогеографических условиях.

\section{Литература}

1. Агаджанян Н.А., Марачев А.Г., Бобков Г.А. Экологическая физиология человека. М.: Крук; 1999.

2. Агаджанян Н.А., Петрова П.Г. Человек в условиях Севера. М.: Крук; 1996.

3. Авцын А.П., Жаворонков А.А., Марачев А.Г., Милованов А.П. Патология человека на Севере. М.: Медицина; 1985.

4. Казначеев В.П. Современные аспекты адаптации. Новосибирск: Наука; 1980.

5. Казначеев В.П. Механизмы адаптации человека в условиях высоких широт. Л.: Медицина; 1980.

6. Фейгенбаум X. Эхокардиография. Пер. с англ. под ред. В.В.Митькова. М.: Видар; 1999.

7. Шиллер Н., Осипов М.А. Клиническая эхокардиография. М.: Практика; 2005.

8. Сандриков В.А., Митьков В.В. (ред). Клиническое руководство по ультразвуковой диагностике. М.: Видар; 1999.

9. Никитин Н.П., Клиданд Джк. Ф. Применение тканевой миокардиальной допплер-эхокардиографии в кардиологии. Кардиология 2002; 3: 66-79.

\section{Информация об авторах}

Ердакова Татьяна Константиновна - к. м. н., руководитель лаборатории инструментальных методов исследования ГУ НИИ МПКС РАМН; тел.: (34995) 9-71-48; e-mail: nii-mpks@mail.ru

Саламатина Людмила Викторовна - д. м. Н., проф., заместитель директора по научной работе ГУ НИИ МПКС РАМН; тел.: (34995) 9-71-48; e-mail: nii-mpks@mail.ru

Буганов Анатолий Алексеевич - член-корр. РАМН, д. М. н., проф.; тел.: (34995) 9-71-48; e-mail: nii-mpks@mail.ru

Поступила 15.05 .09

(с) Коллектив авторов, 2009 удк 616.131-008.1-092(1-17) 